\title{
Extinction revisited: Similarities between extinction and reductions in US intensity in classical conditioning of the rabbit's nictitating membrane response
}

\author{
E. JAMES KEHOE and NATASHA E. WHITE \\ University of New South Wales, Sydney, New South Wales, Australia
}

\begin{abstract}
The mechanisms of extinction were examined by reducing the intensity of the unconditioned stimulus (US) after acquisition training to determine whether such reductions lie on a continuum with CS-alone extinction. The experiments revealed that reductions in US intensity yielded extinction-like effects. Specifically, there were proportional reductions in the daily mean level of responding across sessions. There were also persistent within-session declines and between-session increases of responding analogous to spontaneous recovery. Surprisingly, even when US intensity was held constant, within-session declines and between-session increases were apparent. The results are discussed with respect to possible contributions from unlearning, new learning, generalization decrement, and nonassociative loss, especially CS-specific attentional changes and CR-specific reactive inhibition.
\end{abstract}

The present experiments examined the effects of reducing the intensity of the unconditioned stimulus (US) in comparison with the well-known effects of removing it altogether in conditioned stimulus alone (CS-alone) extinction training. These experiments stem from a simple but important question that cuts across the entire range of theories concerning extinction. Specifically, does the absence of the US constitute a zero point on the continuum of US intensity? Or put another way, does a very weak but detectable US act like the absence of the US? If so, using a weak US after using a strong US should yield the hallmarks of extinction-namely, an overall decline in responding across sessions, punctuated by spontaneous recovery.

Empirical comparisons of reductions in the US versus removal of the US are sparse. In fact, we could find only one published report. In a study of conditioned suppression in rats, Rescorla and Heth (1975) conducted initial training with a strong US. Subsequently, they either conductedCSalone extinction training or reduced the US to an intensity that was detectable but could not support conditioning. They found that, in both cases, suppression disappeared at about the same rate. However, they did not examine the effects of moderate reductions in US intensity to levels that could support conditioning, nor did they report whether or not any recovery of responding occurred between sessions.

Looking further afield, there have been investigations concerning the effects of reductions in US intensity in clas-

Preparation of this manuscript was supported by Australian Research Council Grant A79917018. Correspondence concerning this article should be sent to E. J. Kehoe, School of Psychology, University of New South Wales, Sydney, NSW 2052, Australia (e-mail: j.kehoe@ unsw. edu.au). sical conditioning (Hoehler \& Leonard, 1981) and in reward magnitude in instrumental conditioning (Booream \& Flowers, 1974; Capaldi \& Ziff, 1969; Cox, 1975; Flaherty, 1982;Zeaman, 1949). These studies have consistently shown that such reductions did not maintain responding but led to a decrease in the response asymptote. However, other than a single passing mention by Collier, Knarr, and Marx (1961), none of these studies reported whether betweensession increases analogous to spontaneous recovery appeared. Moreover, none of these studies ever compared changes following a reduction in reinforcer magnitude with nonreinforcement.

The available theories of extinction do not take a firm stance on whether or not there is continuity between weak USs and the absence of the US. There are four main approaches to extinction: unlearning, new learning, generalization decrement, and nonassociative loss (Robbins, 1990). As will be described in the General Discussion section, all four approaches can be modified and intermixed, with various degrees of success, to accommodate findings either for or against a continuity between weak USs and removal of the US. In the face of this theoretical uncertainty, a clear picture of the comparative effects of weak USs versus removal of the US help to narrow the range of plausible assumptions about extinction processes within each type of theory.

\section{EXPERIMENT 1}

In Experiment 1, we investigated the pattern of conditioned responding that occurs when a reduced US, as compared with no US, is presented following initial training with a strong US. Specifically, after initial acquisition of 
the conditioned response (CR) with a 4-mA shock US, each of four groups was presented with a lower US intensity. In addition to CS-alone extinction (no US), three reduced US intensities were used: $0.5,1$, and $2 \mathrm{~mA}$. The latter two values are known to produce reliable $\mathrm{CR}$ acquisition in the rabbit nictitating membrane (NM) preparation (Napier, Macrae, \& Kehoe, 1992; Smith, 1968).

\section{Method}

Subjects. Naive female albino rabbits (Oryctolagus cuniculus) were used $(N=32)$. They weighed approximately $1.5 \mathrm{~kg}$ on arrival. All were housed in individual cages and had unlimited access to food and water.

Apparatus. The apparatus and the recording procedure for the NM response were patterned after those described by Gormezano (1966). The rabbits were trained individually in one of eight soundattenuating chambers. On the wall of each chamber in front of the subject was a stimulus panel. A speaker was mounted at the midpoint of the stimulus panel, $8 \mathrm{~cm}$ anterior to and $16 \mathrm{~cm}$ above the rabbit's head. The speaker provided an auditory CS, which was a 1000$\mathrm{Hz}, 88-\mathrm{dB}$ (SPL) tone of 250-msec duration superimposed on an ambient noise level of $81 \mathrm{~dB}$ (SPL), which was produced by an exhaust fan situated behind each subject. The US was a 50-msec, 50$\mathrm{Hz}$ AC current delivered via stainless steel Autoclip wound clips positioned $10 \mathrm{~mm}$ apart and $15 \mathrm{~mm}$ posterior to the dorsal canthus of the rabbit's right eye. On CS-US trials, the interstimulus interval between the onset of the CS and the onset of the US was $250 \mathrm{msec}$. Mounted on the stimulus panel $4 \mathrm{~cm}$ above the speaker was an 8 -W neon light that served as a houselight. The presentation of stimuli and response recording were controlled by an Apple II computer equipped with interfaces and software developed by Scandrett and Gormezano (1980).

During training, each rabbit was restrained in a Perspex box $(45 \times$ $14 \times 22 \mathrm{~cm}$ ) and was held in place by having its head inserted through an adjustable stock and its ears secured to the front of the stock with a polyurethane foam-covered metal clamp. A muzzlelike head set, fitted securely about the snout, supported a photoelectric transducer for detecting movements of the NM (Gormezano \& Gibbs, 1988). A small hook was attached to a silk loop sutured into the NM of the rabbit's right eye. The hook was connected to one end of an L-shaped crank that operated the photoelectric transducer. The signal from the transducer was amplified and transmitted to an analogto-digital converter mounted in the computer.
Procedure. All the rabbits received 1 day of preparation and 1 day of adaptation before training began. On the preparation day, the hair surrounding each rabbit's right eye was removed, and a small loop of surgical silk (000 Dynex) was sutured into, but not through, the $\mathrm{NM}$ of the right eye, under local anaesthetic (proxymetacaine hydrochloride). The rabbits were then returned to their home cages. On the adaptation day, the rabbits were placed in the conditioning apparatus for $60 \mathrm{~min}$, but neither the CS nor the US was presented.

On the 3rd day following adaptation, the rabbits were randomly assigned to one of four groups $(n=8)$. Stage 1 , acquisition training, was the same for all groups, each receiving $100 \mathrm{CS}-\mathrm{US}$ trials per day for 4 days, in which the US intensity was $4 \mathrm{~mA}$. After training with the 4-mA US, Stage 2 involved the presentation of a different level of US intensity to each of the four groups. The CS-alone extinction group (Group 4-0) received $100 \mathrm{CS}$-alone trials per day. The second, third, and fourth groups received $100 \mathrm{CS}-\mathrm{US}$ trials per session in which the US intensity was $0.5 \mathrm{~mA}$ (Group 4-0.5), $1 \mathrm{~mA}$ (Group 41), and $2 \mathrm{~mA}$ (Group 4-2), respectively. This stage lasted for 5 days. Stage 3, reacquisition, lasted for 1 day. All four groups received five test presentations of the CS to reveal any residual between-session increases in responding and then $100 \mathrm{CS}-\mathrm{US}$ pairings in which the US intensity was restored to $4 \mathrm{~mA}$. The mean intertrial interval (ITI) was $36 \mathrm{sec} \pm 5 \mathrm{sec}$ for all groups in all three stages.

Response definition. A CR was defined as any extension of the NM exceeding $0.5 \mathrm{~mm}$ that occurred during a $250-\mathrm{msec}$ period following the onset of the CS.

Statistical analysis. The data from 4 rabbits, 1 from each group, were excluded from all analyses because they failed to show any CR acquisition during Stage 1 training. Therefore, the data were analyzed using 7 subjects in each group. In all statistical analyses, the rejection level was set according to a Type I error rate of .05.

\section{Results}

Stage 1: CR acquisition. The left side of Figure 1 depicts the mean CR likelihood during each 10-trial block for the 4 days of acquisition. Inspection of Figure 1 reveals that all four groups uniformly acquired CRs and reached a level around $80 \%$ CRs by Day 4 . Any apparent differences among the groups during Stage 1 failed to reach significance $\left(F_{\mathrm{S}}<1\right)$. Further inspection of the data reveals that, within the training sessions on Days 3 and 4, declines in responding emerged. This pattern was confirmed by a significant interaction of the upward linear trend across ses-
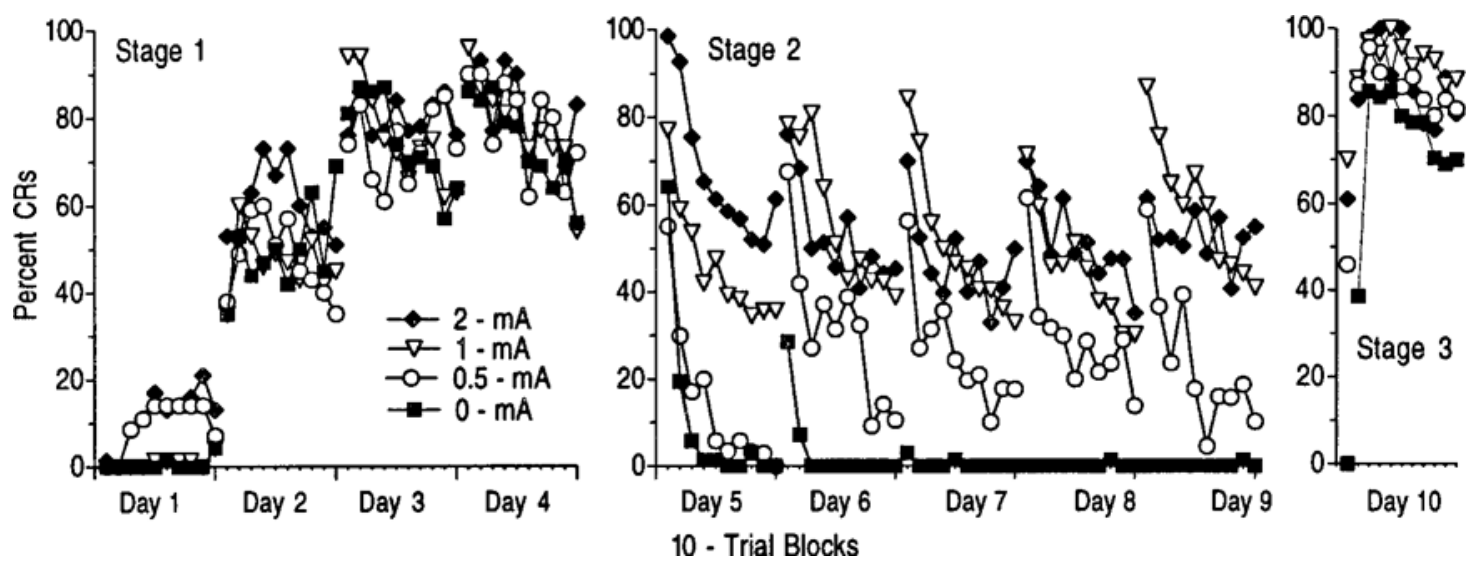

Figure 1. Mean percentages of conditioned responses (CRs) in Stage 1 (initial training with a 4-mA US) and Stage 2 (training with a 0-, 0.5-, 1-, or 2-mA US) in Experiment 1. 
sions $\times$ linear trends within sessions $[F(1,24)=47.55$, $\left.M S_{\mathrm{e}}=737.55, p<.01\right]$. Post hoc tests confirmed that, within sessions, there was a significant linear increase during Day $1\left[F(1,24)=13.76, M S_{\mathrm{e}}=1,357.11, p<.01\right]$, no significant linear or quadratic trends on Day 2, a linear decrease on Day $3\left[F(1,24)=10.34, M S_{\mathrm{e}}=548.66, p<\right.$ $.01]$, and a linear decrease on Day $4[F(1,24)=10.34$, $\left.M S_{\mathrm{e}}=548.66, p<.01\right]$. Between days, however, there was a pronounced rise in responding between the last block of each session and the first block of the next ses$\operatorname{sion}\left[F(1,24)=43.35, M S_{\mathrm{e}}=570.87, p<.01\right]$. Post hoc tests confirmed that, between each pair of days, the betweensession increase was significant [smallest $F(1,24)=7.46$, $\left.M S_{\mathrm{e}}=1107.16, p<.05\right]$.

Stage 2: CR likelihood. The middle panel of Figure 1 shows the likelihood of CRs during each 10-trial block for the 5 days of Stage 2. As may be apparent, all the groups showed significant declines in responding within each session [linear trend $F(1,24)=66.86, M S_{\mathrm{e}}=1696.28, p<$ $.01]$. Group 4-0 showed the most complete reduction in CR likelihood. At the end of each day, no CRs could be detected. Groups 4-0.5, 4-1, and 4-2 showed smaller declines. In the last block of each day of Stage 2, the mean CR likelihoods were 10\%,35\%, and 50\% CRs, respectively.

Between-session recovery in responding was also evident in all the groups. This was confirmed by a significant increase between the last block of each session and the first block of the next session for Days 6-9 $[F(1,24)=79.62$, $\left.M S_{\mathrm{e}}=697.64, p<.01\right]$. Group 4-0, the CS-alone extinction group, showed a reduction in recovery across days, so that by Day 7, recovery was no longer evident. In contrast, Groups 4-0.5, 4-1, and 4-2 showed recovery between sessions that persisted throughout Stage 2. On the first block of Days 6-9, each of these groups showed mean levels of $60 \%, 80 \%$, and $70 \%$ CRs, respectively. These levels were all higher than the level of responding at the end of the previous day. The difference in the persistence of betweensession recovery in the reduced US groups versus CSalone extinction (Group 4-0) was confirmed by a significant interaction of US intensity (quadratic trend) $\times$ blocks [the difference between the last block and the first block of adjacent sessions; $F(1,24)=22.73, M S_{\mathrm{e}}=697.64$, $p<.01]$.

In addition to the sawtooth pattern of within-session declines and between-session increases, there were reductions in responding proportional to the reduction in the US intensity. There was a significant days (linear) $\times$ groups (quadratic) interaction $\left[F(1,24)=4.27, M S_{\mathrm{e}}=2,962.72\right.$, $p<.05]$. Averaged across the 5 days of extinction, Groups 4-0, 4-0.5, 4-1, and 4-2 showed mean CR likelihoods of $3 \%, 25 \%, 50 \%$, and $55 \%$ CRs, respectively. Statistical analysis revealed a significant linear trend in overall responding across groups as a function of their US intensity in Stage $2\left[F(1,24)=21.79, M S_{\mathrm{e}}=26,484.15, p<\right.$ $.01]$.

Stage 2: Unconditioned response likelihood. Lowering US intensity may have produced a partial reinforce- ment schedule, in which the animals detected the US on some trials, but not on others. Previously, in the rabbit NM preparation, Gibbs, Latham, and Gormezano (1978) deliberately introduced a range of partial reinforcement schedules after initial training, using a $100 \%$ reinforcement schedule. In groups receiving 50\%, 25\%, and 15\% partial reinforcement, the CR likelihood dropped only slightly; specifically, CRs occurred on $97 \%, 95 \%$, and $80 \%$ of all trials, respectively. Large declines in responding appeared only in a 5\% partial reinforcement group. In that group, CR likelihood sank to a level of $45 \%$ by the sixth session of partially reinforced training.

To test how reliably the reduced US elicited the unconditioned response (UR) in the present experiment, the likelihood of a UR was estimated for all four groups. Because the CR tended to blend with the UR, the frequency of URs was determined indirectly by measuring all responses initiated during an 800-msec interval that encompassed the 250-msec CS, the 50-msec US, and a 500msec period following US offset. Thus, CRs, URs, and blended responses were all counted. If a reduced US reliably elicited the UR, response likelihood would be at or near $100 \%$, regardless of the number of CRs.

There was a significant reduction in UR likelihood as a function of reductions in US intensity $[F(1,24)=34.19$, $\left.M S_{\mathrm{e}}=13,122.81, p<.01\right]$. Specifically, Group 4-0.5 showed the greatest reduction in UR likelihood to $45 \%$. This level corresponds approximately to a $50 \%$ partial reinforcement schedule, which Gibbs et al. (1978) found yielded a negligible reduction in CR likelihood. In the other two groups in the present experiment, the reductions in UR likelihood were slight: Groups 4-1 and 4-2 showed UR likelihoods of $85 \%$ and $97 \%$, respectively. With reference to Gibbs et al.'s results, none of the reductions in UR likelihood in the present experiment produced a lean enough partial reinforcement schedule to explain the overall declines in daily CR likelihood.

Stage 3: CR reacquisition. In the right panel of Figure 1 , the isolated points represent the level of responding during the five CS-alone trials at the start of Stage 3. Group 4-0 showed no CRs, which confirmed that spontaneous recovery had been eradicated during CS-alone extinction. Responding in the other groups showed a level of between-session recovery similar to that seen during Stage 2.

When all the groups once again received pairings of the CS with the original 4-mA US, they all reacquired high levels of responding to a mean level of $85 \% \mathrm{CRs}$, which was comparable to the level seen on the last day of Stage 1. Group 4-0 initially lagged behind the other three groups but rapidly converged with them. Specifically, Group 4-0 reached a level of $40 \%$ in the first block of 10 pairings, before increasing to a level of $85 \% \mathrm{CRs}$. The other three groups rose to an $85 \%$ level within the first block of pairings. This initial difference across US intensity levels was significant [linear trend $F(1,24)=7.16, M S_{\mathrm{e}}=1,164.22$, $p<.05]$. 


\section{Discussion}

When US intensity was reduced, both hallmarks of conventional extinction appeared. That is, the daily mean level of responding declined across sessions, and recovery in responding appeared between sessions. In Groups 4-0.5, 4-1, and 4-2, the overall decline in responding across days was proportional to the reduction in US intensity. Furthermore, in these groups, a sawtooth pattern of declines within sessions and increases between sessions persisted throughout Stage 2. In these respects, the ultimate disappearance of the CR and eradication of spontaneous recovery in CS-alone extinction, as in Group 4-0, appears to be a consequence of an extreme reduction in US intensity.

The third stage of training revealed that the reintroduction of the original 4-mA US yielded rapid restoration of responding to the levels seen at the end of initial acquisition. Group 4-0, in which responding had been thoroughly extinguished, confirmed previous findings that reacquisition of CRs in the rabbit NM preparation is very rapid (Macrae \& Kehoe, 1999; Napier et al., 1992). As in the previous studies, care was taken in the present experiment to ensure that spontaneous recovery had been eradicated in Group 4-0 prior to reacquisition training. The previous studies also included rest control groups to provide an appropriate between-group comparison. Although the present experiment did not include a rest control, the speed of reacquisition can be appreciated by comparing the acquisition curves on Day 1 versus Day 10. In Group 4-0, few CRs appeared on Day $1(M=1 \%)$, whereas a much larger number of CRs appeared on Day $10(M=74 \%)$. In Groups $4-0.5,4-1$, and $4-2$, reacquisition appeared to be equally rapid, fueled by a combination of between-session recovery followed by the full restoration of responding during the pairings of the CS with the 4-mA US.

The rapid reacquisition in all four groups in Stage 3 provides an additional point of continuity between reduced USs and CS-alone extinction, at least in the rabbit NM preparation. Rapid reacquisition following a weak US was not a guaranteed outcome. Training with the weak US could have interfered with subsequent reacquisition based on the stronger US (cf. Ayres, Moore, \& Vigorito, 1984). Further afield, there is recent evidence that rapid reacquisition can be considerably diminished in the rabbit NM preparation when there is massively extended extinction training-for example, $27 \mathrm{CS}$-alone trials for every original CS-US trial (Kehoe \& Weidemann, 2001; Medina, Garcia, \& Mauk, 2001). These recent findings are heading in the direction of the retardation in reacquisition that has been seen in rats when extended extinction has been conducted (Bouton \& Swartzentruber, 1986, 1989; Carlton, Mitchell, \& Schachtman, 1996; Hart, Bourne, \& Schachtman, 1995; but see Aguado, de Brugada, Hall, \& Agate, 2001).

The appearance of within-session declines and betweensession recovery near the end of Stage 1 before reductions in the US was surprising. Within-session changes in responding under constant conditions have been reported widely for operant procedures (e.g., Aoyama \& McSweeney, 2001; McSweeney \& Roll, 1993). For the rabbit NM preparation, however, within-session decreases under constant reinforcement have been observed only occasionally (Tait, Kehoe, \& Gormezano, 1983), and certainly not commonly (e.g., Macrae \& Kehoe, 1999; Napier et al., 1992).

\section{EXPERIMENT 2}

Experiment 2 repeated Group 4-2 and compared it with a control group that had a constant 2-mA US in Stages 1 and 2 (Group 2-2). Stage 3 in Experiment 2 entailed CSalone extinction training, rather than reacquisition training. Extinction training was conducted to determine whether any effects of the initial training with the 4-mA US in Group 4-2 would affect extinction of the CR. The 2-mA US was chosen as the weaker US, because in Experiment 1, it elicited the UR with near-perfect consistency (97\%). Thus, any differences between the two groups at any stage of the experiment could be attributed to the effects of US intensity, and not to the inadvertent introduction of partial reinforcement.

Group 2-2 was included for two reasons. First, it provided a baseline for determining whether responding following the reduction in US intensity in Group 4-2 would drop to a level that was greater than, less than, or equal to the performance obtained with a constant 2 -mA US. Second, Group 2-2 also provided a comparison condition for determining whether the within-session declines and between-session increases seen in Group 4-2 would appear with a constant lower intensity US.

\section{Method}

Subjects. The subjects were 16 naive female albino rabbits.

Apparatus and Procedure. The apparatus and procedure for Experiment 2 were the same as those described for Experiment 1, unless otherwise indicated. On the 3rd day following adaptation, the rabbits were randomly assigned to one of two groups $(n=8)$. Stage 1, acquisition training, involved both groups' receiving 100 CS-US trials per day for 4 days. Group 4-2 was trained with a 4-mA US, and Group 2-2 received training with a 2-mA US. In Stage 2, both groups were trained with the 2-mA US. There were $100 \mathrm{CS}-\mathrm{US}$ trials per day for 6 days. Stage 3 entailed CS-alone extinction training for both groups. For 2 days, both groups were presented with $100 \mathrm{CS}$-alone trials.

Statistical analysis. The data from 1 rabbit in Group 2-2 were excluded from all analyses because the rabbit failed to show any CR acquisition during Stage 1 . Therefore, the data were analyzed using 8 subjects in Group 4-2 and 7 subjects in Group 2-2.

\section{Results}

Stage 1: CR acquisition. The left side of Figure 2 depicts the mean CR likelihood of Group 4-2 and Group 2-2 during each 10-trial block in Stage 1. Group 4-2 showed greater CR acquisition than did Group 2-2 $[F(1,13)=$ $\left.8.28, M S_{\mathrm{e}}=2,124.59, p<.05\right]$. CR likelihood in Group 42 rose to a level of $90 \%$ by the beginning of Day 4, whereas Group 2-2's responding reached only 55\%. 



Figure 2. Mean percentages of conditioned responses (CRs) in Stage 1 (initial training with either a 4-mA US or a 2-mA US) and Stage 2 (training with a 2-mA US) in Experiment 2.

Further inspection of the figure reveals a pattern of within-session and between-session changes similar to that seen in Stage 1 of Experiment 1. Within sessions, there was a significant linear increase during Day 1 $\left[F(1,13)=4.46, M S_{\mathrm{e}}=11,275.57, p<.05\right]$, no significant trends on Day 2, a significant linear decrease on Day 3 $\left[F(1,13)=15.11, M S_{\mathrm{e}}=610.02, p<.01\right]$, and a downward linear trend on Day 4 that failed to reach statistical significance $\left[F(1,13)=3.47, M S_{\mathrm{e}}=2,866.38, p=.09\right]$. Between each pair of days, there was a significant rise in responding between the last block of each session and the first block of the next session [smallest $F(1,13)=5.77$, $\left.M S_{\mathrm{e}}=716.04, p<.05\right]$.

Stage 2: CR likelihood. The mean CR likelihoods during Stage 2 are displayed in the middle of Figure 2. As compared with the difference between the two groups at the end of Stage 1, their overall CR likelihoods converged to a level of around $60 \%$ during Stage 2. Any apparent differences between the two groups in Stage 2 failed to reach statistical significance. Both groups showed a significant decline within each session $\left[F(1,13)=23.61, M S_{\mathrm{e}}=\right.$ $2,594.22, p<.01]$ and a significant recovery from the last block of each session to the first block of the next session $\left[F(1,13)=30.75, M S_{\mathrm{e}}=1181.69, p<.01\right]$.

Stages 1 and 2: UR likelihood. The estimated UR likelihood was above $95 \%$ for both groups. There was no evidence of any difference between the two groups in either Stage 1 or Stage 2.

Stage 3: CS-alone extinction. When both groups were given CS-alone extinction training for 2 days, they showed the same pattern of responding. As is depicted in the righthand portion of Figure 2, both groups began Stage 3 with high CR likelihoods, and responding declined rapidly to zero by the middle of the first session. At the start of the second session, significant spontaneous recovery appeared $\left[F(1,13)=11.61, M S_{\mathrm{e}}=841.28, p<.01\right]$, after which responding again dropped to zero by the middle of the session. The within-session declines were confirmed by a significant downward linear trend across blocks $\left[F(1,13)=46.75, M S_{\mathrm{e}}=1,224.51, p<.01\right]$. Any apparent differences between the two groups failed to reach statistical significance.

\section{Discussion}

The results of Experiment 2 confirmed and extended those of Experiment 1. In agreement with Experiment 1, extinction-like effects appeared following a reduction in US intensity. That is, in Group 4-2, there was an overall reduction in responding across days, punctuated by recovery between sessions. In addition, the present results confirmed that within-session declines and between-session increases appeared before a reduction in US intensity. This pattern was not confined to the 4-mA US used in Group 42 but appeared also with the 2-mA US throughout training in Group 2-2. Finally, in Stage 3, in which the US was absent, both groups showed similar and conventional patterns of CS-alone extinction, in which responding declined rapidly within the first session, followed by spontaneous recovery and a subsequent decline in the next session.

\section{EXPERIMENT 3}

The results of Experiments 1 and 2 demonstrated that reductions in US intensity caused effects continuous with those of CS-alone extinction. However, the results also revealed that within-session declines and between-session increases occurred even without reducing US intensity. This latter finding suggests that a decremental performance factor was superimposed on the overall level of responding determined by US intensity.

The most obvious candidate for a decremental performance factor is motor fatigue arising from repeated elicitation of the UR and CR. Accordingly, Experiment 3 was intended to replicate the design of Experiment 2 but to minimize the potential impact of motor fatigue in two ways. The number of trials per session was reduced from 100 to 20 , and the ITI was increased from 36 to $90 \mathrm{sec}$ to allow more time for any motor fatigue to dissipate.

\section{Method}

Subjects. There were 16 naive albino rabbits in Experiment 3.

Apparatus and Procedure. The apparatus and procedure for Experiment 3 were the same as those described for Experiment 2, unless otherwise indicated. In brief, Stage 1 involved both groups' receiving 20 CS-US trials per day for 4 days. Group 4-2 was trained with the 4-mA US, and Group 2-2 was trained with the 2-mA US. 
In Stage 2, both groups were trained with the 2-mA US. There were 20 CS-US trials per day for 12 days. Stage 3 entailed CS-alone extinction training, in which both groups were presented with $20 \mathrm{CS}$ alone trials on each of 2 days. The mean ITI in all three stages was $90 \mathrm{sec} \pm 5 \mathrm{sec}$.

Statistical analysis. The data from 1 rabbit in each group were excluded from all analyses because it failed to show any CR acquisition during Stage 1. Therefore, the data were analyzed using 7 subjects in each group.

\section{Results}

Stage 1: CR acquisition. The left side of Figure 3 shows the acquisition curves for both groups in Experiment 3 . As in Experiment 2, Group 4-2 showed CRs earlier and reached a higher asymptote than did Group 2-2. However, this apparent difference in initial CR acquisition failed to reach statistical significance. In both groups, no evidence of within-session declines appeared as they reached asymptote on Days 3 and 4. Statistically, there was a significant upward linear trend both within sessions $[F(1,12)=$ $\left.12.08, M S_{\mathrm{e}}=390.95, p<.01\right]$ and across days $[F(1,12)=$ $\left.66.32, M S_{\mathrm{e}}=2,608.57, p<.01\right]$. Responding in the last block of each session tended to be higher than responding in the first block of the session, but no between-session increase was statistically significant (all $p$ s $>.10$ ).

Stage 2: CR likelihood. The middle portion of Figure 3 shows the CR likelihood for both groups over the 10 days of Stage 2. Both groups showed a sawtooth pattern of within-session declines and between-session recovery. Statistical comparisons confirmed that there was a significant downward linear trend within sessions $[F(1,12)=20.12$, $\left.M S_{\mathrm{e}}=1,626.41, p<.01\right]$ and a significantincrease between the last block of each session and the first block of the next session $\left[F(1,12)=20.46, M S_{\mathrm{e}}=1,287.20, p<.01\right]$.

Across days, some differences between groups emerged so that, by the end of Stage 2, Group 4-2 responded less than did Group 2-2. Although suggestive of a negative contrast effect, the differences between the groups were more impressive visually than they were statistically. The overall difference in responding between Group 4-2 $(M=$ $49 \%)$ versus Group 2-2 $(M=81 \%)$ failed to even approach significance $\left(F<1, M S_{\mathrm{e}}=6,928.05\right)$. The test for a groups $\times$ days (linear) interaction also failed to reach statistical significance $\left[F(1,12)=3.56, M S_{\mathrm{e}}=2,902.67\right.$, $p=.09]$. An examination of the $M S_{\mathrm{e}}$ error terms for both these comparisons indicates that the variances between and within groups was in the range of those obtained in the other experiments in this series.

Stages 1 and 2: UR likelihood. The UR likelihoods were above 95\% for both groups across Stages 1 and 2 .

Stage 3: CS-alone extinction. Both groups showed a conventional extinction pattern. Within each of the two sessions, there was a significant decline in responding $\left[F(1,12)=29.97, M S_{\mathrm{e}}=932.16, p<.01\right]$. Between the two sessions, there was significant recovery $[F(1,12)=$ $\left.18.84, M S_{\mathrm{e}}=392.56, p<.01\right]$. Across the 2 days, the overall levels of responding failed to differ significantly between the two groups $(F<1)$.

\section{Discussion}

Experiment 3 confirmed the results of Experiments 1 and 2 that reductions in US intensity produce extinctionlike effects. Moreover, when CS-alone extinction was conducted in Stage 3, a conventional pattern of responding appeared. Experiment 3 also confirmed that within-session declines and between-session increases can appear even when US intensity is held constant at a moderate value, as it was for Group 2-2.

Regarding within-session declines and between-session increases, Experiment 3 was designed to reduce the potential impact of a nonspecific performance factor like motor fatigue. Despite a reduction in the number of trials per session and an increase in the ITI, a decremental performance factor appeared to be operating as strongly as it did under more massed training. For example, in Experiment 2, within-session declines began to appear in Group 22 on Day 2 after a total of 100 CS-US pairings on Day 1. In the present experiment, within-session declines began to appear in Group 2-2 on Day 5, after a total of 80 CS-US pairings distributed across Days 1-4.

\section{EXPERIMENT 4}

Experiment 4 was essentially a replication of Experiment 3 , but with one key addition. In order to balance the



Figure 3. Mean percentages of conditioned responses (CRs) in Stage 1 (initial training with either a 4-mA US or a 2-mA US) and Stage 2 (training with a 2-mA US) in Experiment 3. 
total exposure to the US, all the animals received the same number of presentations of the 4-mA US and the 2-mA US in every training session. That is, Group 4-2 in this experiment initially received 20 CS-US pairings with the 4mA US, just as did its counterpart in Experiment 3. In addition, Group 4-2 received 20 US-alone presentations of the 2-mA US, interpolated among the CS-US pairings. In Stage 2, Group 4-2 received 20 pairings of the CS with the 2 -mA US plus 20 US-alone presentations of the 4-mA US. Group 2-2 received pairings of the CS with the 2-mA US throughout Stages 1 and 2, plus interpolated presentations of the 4-mA US. In Stage 3, both groups received CS-alone presentations intermixed with presentations of the 2-mA and 4-mA USs.

Equating both groups for exposure to the US throughout the experiment was designed to hold constant any contribution from performance factors, such as motor fatigue and arousal level (Hoehler \& Leonard, 1981; Spence, 1958; Spence, Haggard, \& Ross, 1958). In order to detect the contribution of such performance factors, the USalone presentations also allowed measurement of the UR over trials separately from any direct influence of the CS or CR. Finally, initial acquisition training was extended from 4 to 8 days in order to determine whether withinsession declines in the CR or the UR would appear in either group prior to the reduction of the paired US intensity in Group 4-2.

\section{Method}

Subjects. There were 16 naive, albino rabbits in Experiment 4.

Apparatus and Procedure. The apparatus and procedure for Experiment 4 were the same as those used in Experiment 3, unless otherwise indicated. The rabbits were randomly assigned to one of two groups $(n=8)$. Stage 1 entailed both groups' receiving 20 CS-US trials in each session for 8 days. Group 2-2 received training with a 2-mA US, and Group 4-2 was trained with a 4-mA US. During each day of Stage 1, both groups also received 20 presentations of the other US, intermixed with the CS-US trials. The CS-US trials and the US-alone trials were randomly intermixed, with the one constraint that no more than three of either trial type should be presented consecutively. The mean ITI was $45 \mathrm{sec}$.

In Stage 2, both groups received $20 \mathrm{CS}-\mathrm{US}$ trials per day in which the intensity of the US was $2 \mathrm{~mA}$. At the same time, both groups received 20 US-alone presentations in which the US intensity was $4 \mathrm{~mA}$. Stage 2 lasted for 8 days. The CS-US trials and the US-alone presentations were randomly intermixed, using the same constraint as that used in Stage 1.

Stage 3 entailed unpaired extinction training. For 2 days, the rabbits were all presented with $20 \mathrm{CS}$-alone trials in each session. They were also presented with 20 US-alone trials with a 2-mA US and a further $20 \mathrm{US}$-alone trials in which a 4-mA US was used. The three types of trial were randomly intermixed, but with the constraint being that each block of 3 trials should contain one presentation of each stimulus.

Statistical analysis. The data from one rabbit in Group 2-2 were removed from all analyses because the rabbit failed to show CR acquisition in Stage 1. Therefore, the data were analyzed using 8 subjects in Group 4-2 and 7 subjects in Group 2-2.

\section{Results}

Stage 1: CR acquisition. The left side of Figure 4's upper portion shows the acquisition curves for both groups.
As can be seen in the figure, Group 4-2 acquired CRs more quickly and to a higher level than did Group 2-2. By the end of Day 4, Group 4-2 was responding with a likelihood of $95 \%$, at which level it continued to respond for the remaining 4 days of Stage 1. Group 2-2 acquired CRs more slowly and reached a level of $45 \%$ by Day 8 . Statistical analysis confirmed that the two groups differed in their overall level of responding in Stage $1[F(1,13)=21.22$, $\left.M S_{\mathrm{e}}=10,515.28, p<.01\right]$ and in their linear trends across days $\left[F(1,13)=6.45, M S_{\mathrm{e}}=3,229.59, p<.05\right]$.

An examination of performance in Stage 1 reveals that within-session declines and between-session increases emerged, particularly in Group 2-2. The declines were statistically significant in Group 2-2 on Day $7[F(1,13)=$ $\left.21.15, M S_{\mathrm{e}}=249.78, p<.05\right]$ and Day $8[F(1,13)=8.34$, $\left.M S_{\mathrm{e}}=249.78, p<.05\right]$. However, the only significant between-session increase occurred between Days 5 and 6 $\left[F(1,13)=6.47, M S_{\mathrm{e}}=533.95, p<.05\right]$. For Group 4-2, there was a significant upward linear trend across days $\left[F(1,13)=6.40, M S_{\mathrm{e}}=1,041.18, p<.05\right]$, but the withinsession changes and between-session increases failed to attain significance ( $p$ s $>.05)$.

Stage 1: UR measurements. The UR was elicited reliably by both the 2-mA and the 4-mA USs. In Stage 1, the mean UR likelihood on the 2-mA US-alone trials in Group 4-2 $(M=96 \%)$ was only slightly lower than that on the 4-mA US-alone trials in Group 2-2 $(M=100 \%)$. On CS-US trials, Group 4-2 showed 99\% URs, and Group 22 showed $98 \%$ URs.

A more continuous measure of the UR was provided by using its magnitude, which is the maximal extent of NM closure on each trial, including the zero point if no closure occurs. The left side of Figure 4's lower portion shows the mean magnitude of the UR on both CS-US trials and USalone trials in each group. The measure is expressed in analog/digital counts; 20 counts correspond to $1 \mathrm{~mm}$ of NM movement.

An examination of UR magnitude revealed the following differences. First, the 4-mA US (filled symbols) elicited a significantly larger UR $(M=60)$ than did the 2-mA US [empty symbols; $M=34 ; F(1,13)=81.01, M S_{\mathrm{e}}=179,299$, $p<.01]$. Second, Group 4-2 showed a larger UR to the 4mA US on its CS-US trials $(M=71)$ than did Group 2-2 on its 4-mA US-alone trials $(M=50)$. In contrast, both groups showed virtually identical UR magnitudes $(M \mathrm{~s}=34)$ to the 2-mA US. This pattern was confirmed by a significant interaction $\left[F(1,13)=12.18, M S_{\mathrm{e}}=26,957, p<.01\right]$.

On Day 1, there was a noticeable decline in UR magnitude within the session in both groups on both CS-US trials and US-alone trials. On subsequent days, however, the within-session declines in UR magnitude diminished. By the last few days of Stage 1, UR magnitudes were relatively constant throughout each session. The statistical analysis confirmed that there was a significant interaction of blocks (linear trend) $\times$ days [linear trend; $F(1,13)=$ $\left.12.44, M S_{\mathrm{e}}=2,459, p<.01\right]$. Post hoc tests revealed that, when Days 1 and 2 were excluded, this interaction disappeared $\left[F(1,13)=1.78, M S_{\mathrm{e}}=233, p>.10\right]$. 

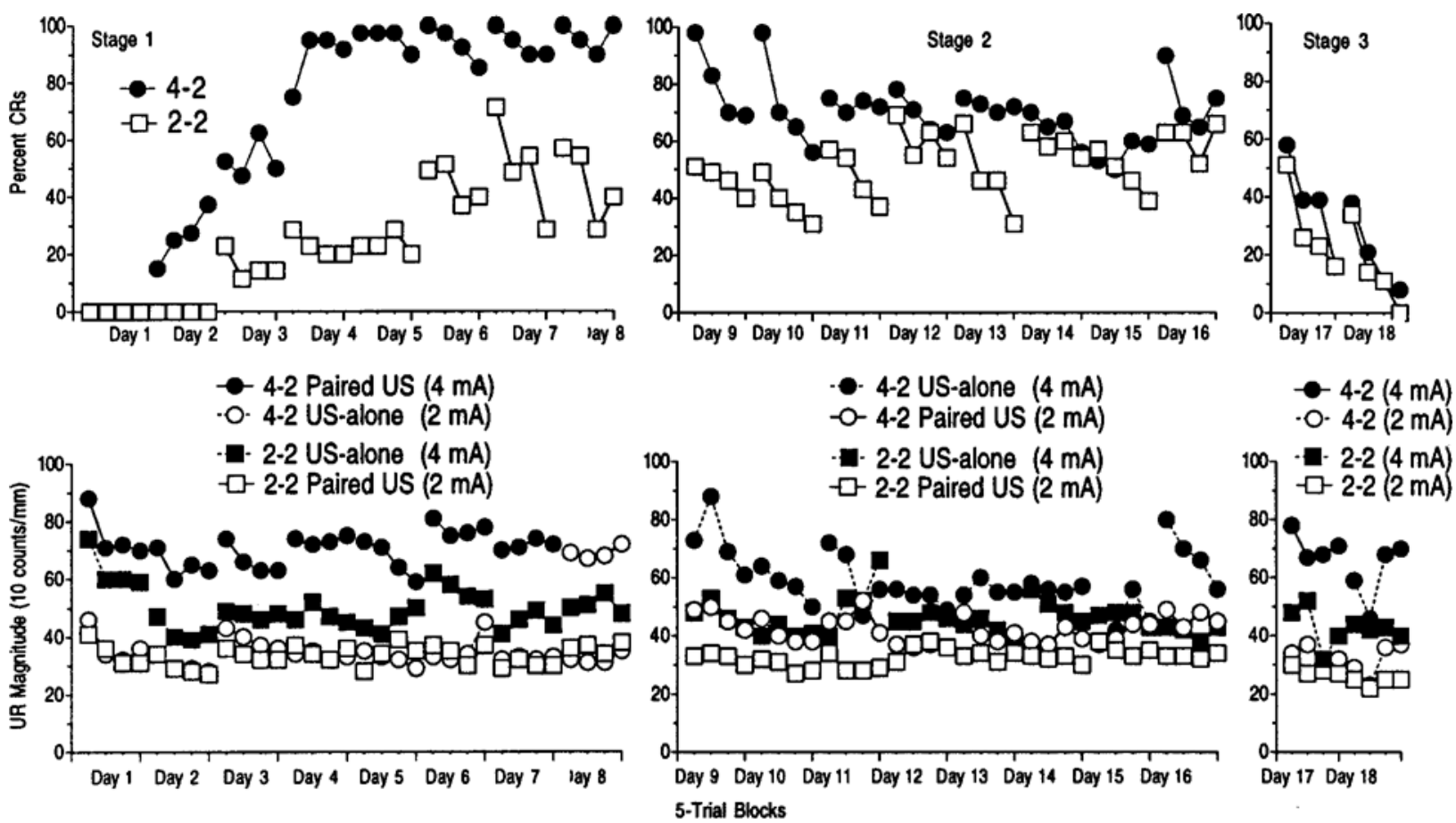

Figure 4. Mean percentages of conditioned responses (CRs) in Stage 1 (using both a 4-mA US and a 2-mA US, one paired with the CS and one presented alone) and Stage 2 (training with a 2-mA US paired with the CS and the 4-mA US presented alone) in Experiment 4.

Stage 2: CR likelihood. The middle panel of Figure 4's upper portion depicts mean CR likelihood during Stage 2. Both groups continued to show within-session declines $\left[F(1,13)=12.40, M S_{\mathrm{e}}=1,041.18, p<.01\right]$ and between-session recovery $\left[F(1,13)=11.70, M S_{\mathrm{e}}=1,167.27\right.$, $p<.01]$. As compared with the difference between the two groups at the end of Stage 1, their overall CR likelihoods converged to a level of around $70 \%$. The overall difference in responding between Group 4-2 $(M=70 \%)$ and Group 2-2 $(M=51 \%)$ did not reach significance $[F(1,13)=$ $1.28, p>.10]$, because there was substantial within-group variance $\left(M S_{\mathrm{e}}=33,888\right)$. Likewise, interactions entailing the groups factor did not reach statistical significance.

Stage 2: UR measurements. In Stage 2, both groups received the 2-mA US on CS-US trials and the 4-mA US on US-alone trials. Both groups responded at a likelihood of $98 \%$ on both CS-US trials and US-alone trials. The UR magnitudes, shown in the middle panel of Figure 4, were significantly higher on the 4-mA trials $(M=52)$ than on the 2-mA trials $\left[M=37 ; F(1,13)=21.82, M S_{\mathrm{e}}=2,689\right.$, $p<.01]$. Although the UR magnitudes were relatively constant within sessions in both groups, Group 4-2 did have three sessions in which the UR on the 4-mA USalone trials was greater at the start of the session than at the end of the session. The requisite interaction of blocks (linear) $\times$ US intensity $\times$ groups approached but failed to reach statistical significance $\left[F(1,13)=4.29, M S_{\mathrm{e}}=\right.$ $172, p<.06]$. Any other apparent differences in UR magnitude among groups, days, or blocks within sessions were not statistically significant.
Stage 3: CR extinction. In Stage 3, in which CS-alone presentations were intermixed with US-alone presentations, conditioned responding declined rapidly in both groups. There was some spontaneous recovery between the two days of Stage 3; CR likelihood in the two groups rose from $16 \%$ to $36 \%$. Statistical tests confirmed a linear decline in responding within sessions $[F(1,13)=26.06$, $\left.M S_{\mathrm{e}}=707.52, p<.01\right]$ and spontaneous recovery between the two sessions $\left[F(1,13)=5.48, M S_{\mathrm{e}}=557.02, p<\right.$ $.05]$. Any apparent differences between the two groups were small and were not statistically significant.

Stage 3: UR measurements. During Stage 3 extinction, both the 2-mA and the 4-mA intensities were presented on US-alone trials. Overall, the 4-mA US consistently elicited larger URs $(M=54)$ than the 2-mA US $[M=29$; $\left.F(1,13)=49.59, M S_{\mathrm{e}}=809, p<.01\right]$. In addition, there was an interaction of groups $\times$ US intensity $[F(1,13)=5.39$, $\left.M S_{\mathrm{e}}=809, p<.05\right]$. Group 4-2, in which the 4-mA US had been paired with the CS in Stage 1, showed larger URs $(M=66)$ than did Group 2-2, in which the 4-mA US had never been paired with the CS $(M=43)$. Both groups showed similar-sized URs to the 2-mA US. Specifically, Groups 4-2 and 2-2 showed mean magnitudes of 33 and 26 , respectively.

\section{Discussion}

When total exposure to the US was controlled, the pattern of results in Experiment 4 still corresponded to those seen in the previous experiments. When the US intensity was reduced in Group 4-2, overall responding dropped 
and converged with that of Group 2-2. Significant withinsession declines and between-session increases appeared in both groups, both in Stage 1 and in Stage 2, as well as in CS-alone extinction in Stage 3.

The measurement of URs throughout this experiment was conducted primarily to determine whether the UR would show evidence of motor fatigue. In fact, withinsession declines and between-session increases in UR magnitude were sparse. When they did appear, they occurred primarily with the 4-mA US, and not with the 2mA US. This pattern differed dramatically from that seen in CR likelihood, for which within-session declines and between-session increases appeared consistently whether the $2-\mathrm{mA}$ or the 4-mA US was paired with the CS.

The absence of within-session declines in UR magnitude cannot be discounted as a lack of sensitivity in that measure. In fact, it was sensitive in two respects. First, the 4-mA US elicited larger URs than did the 2-mA US. Second, there was also evidence that when the 4-mA US was paired with the CS, the magnitude of the UR was facilitated when the 4-mA US was presented alone in Stage 3 (cf. Schreurs, Oh, Hirashima, \& Alkon, 1995; Schreurs, Shi, Pineda, \& Buck, 2000).

\section{GENERAL DISCUSSION}

The results of all four experiments were in good agreement with respect to three main findings. First, the asymptotic level of zero responding in CS-alone extinction appears to lie on a continuum with the effects of other US intensities. Reductions in US intensity following initial acquisition yielded proportional reductions in the overall level of responding. Second, a pattern of within-session declines and between-session recovery of responding, usually seen only during CS-alone extinction, appeared persistently under a wide variety of US intensities and even appeared without reductions in US intensity. This pattern was specific to performance of the CR; a corresponding pattern did not appear reliably in measures of the UR. Third, reductions in US intensity left intact the effects of CS-alone extinction. Specifically, complete removal of the US after reductions in the US yielded reductions in CR likelihood to zero, punctuated by spontaneous recovery (Experiments 2, 3, and 4). Conversely, restoration of the original US intensity yielded evidence for rapid reacquisition of the $\mathrm{CR}$ (Experiment 1). Together, these findings suggest that, as an empirical generalization, the absence of the US is a zero point on the continuum of US intensity.

Although the present findings are empirically clear, they are theoretically perplexing. As was mentioned in the introduction, theories of extinction have been grouped under the headings of unlearning, new learning, generalization decrement, and nonassociative loss. Their mechanisms are not mutually exclusive, and Robbins (1990) has suggested that a fruitful strategy would be to estimate the contribution of each mechanism in each response system under different conditions. We concur with this strategy. Accordingly, this discussion will be divided into five parts. The significance of the present findings for each of the four theoretical groups will be discussed, and finally, conclusions concerning the main contributors will be described.

\section{Unlearning Theories}

In their elementary form, unlearning theories assume that extinction entails associative loss that is the reverse of acquisition. This elementary form of unlearning has been repeatedly challenged since Pavlov's (1927) first observations of spontaneous recovery and rapid reacquisition. Nevertheless, unlearning theories have continued to thrive. Today, they are typified by those that use an error-correction equation to explain both acquisition and extinction (e.g., Bush \& Mosteller, 1951; Gluck \& Thompson, 1987; Mackintosh, 1975; Rescorla \& Wagner, 1972; Sutton \& Barto, $1981,1990)$. In these models, changes in associative strength $(\Delta V)$ depend on the difference between the maximum level of association supportable by the US $(\lambda)$ and the current strength of an association $(V)$. These explanations take the general mathematical form: $\Delta V \infty(\lambda-V)$.

This formula can readily explain the general dependence of acquisition on US intensity and the proportional declines in conditioned responding seen after reductions in US intensity. Specifically, the parameter $\lambda$ is typically assumed to depend on US intensity. Hence, CS-alone extinction reduces $\lambda$ to zero, thereby making $\Delta V$ negative and thus forcing a decline in associative strength until it reaches a zero level. By the same logic, reducing US intensity lowers $\lambda$, and associative strength would be expected to decline until it matches the new value of $\lambda$.

Although the error-correction rule can explain the overall reduction in responding as a function of US intensity, it cannot explain spontaneous recovery in CS-alone extinction or rapid reacquisition. To do so, unlearning theories have included additional mechanisms, the aim of which is to conserve associative strength while still yielding large reductions in responding. Within the unlearning tradition, the most detailed account of spontaneous recovery is stimulus-sampling theory (Estes, 1955; Mazur, 1996). It assumes that a CS generates a large pool of hypothetical stimulus elements. At any one time, only a portion of these are available for sampling, and elements drift randomly in and out of the available set over time. On any one trial, only a subset of the available set is randomly sampled and is thereby eligible for a change in associative strength. Acquisition of the CR therefore reflects an accumulation of elements that have gained excitatory value, and extinction of the $\mathrm{CR}$ represents an accumulation of elements that have lost excitatory value.

According to stimulus-sampling theory, spontaneous recovery is explained by the sampling of excitatory elements that drift back into the available set between extinction training sessions. Eventually, as all the elements lose excitatory value, responding disappears altogether. Although 



Figure 5. Layered networks in which the conditioned stimulus (CS) has associative linkages with an intermediate unit $(X)$, which in turn has associative linkages with an output unit $(Y)$. The unconditioned stimulus (US) sends inputs to both the $\mathrm{X}$ and $\mathrm{Y}$ units.

traditional stimulus-sampling theory assumes that associative strength for each element is gained or lost on an allor-none basis, the associative strength of each element could rise and fall in a continuous fashion if the error-correction rule is used. This change in assumptions would allow stimulus-sampling theory to explain dependence of the asymptotic level of responding on US intensity.

Even with this change in assumptions, stimulussampling theory cannot explain either (1) the appearance of within-session declines and between-session increases when US intensity remains unchanged or (2) the persistence of that pattern after a reduction in US intensity. In general, stimulus-sampling theory predicts that responding should stabilize as the total pool of elements becomes conditioned when a specific US is used. During training with an unchanged US, some new elements might appear on each day of training, but these new elements would tend to reduce responding at the start of a session, not at the end of a session. By the same token, responding following a reduction in US intensity would be expected to show recovery between the first few sessions, but eventually responding should stabilize at a new, lower asymptote.

In addition to spontaneous recovery, rapid reacquisition has long been thought to be fatal for unlearning theories. Previous studies using the rabbit NM response have shown that reacquisition after extinction is rapid, relative to a naive rest control condition (Macrae \& Kehoe, 1999; Napier et al., 1992). This effect was seen in Experiment 1, in which reacquisition after thorough extinction (Group 40 ) was nearly as rapid as reacquistion in the groups that had undergone only a reduction in US intensity.

Rapid reacquisition has been explained in unlearning theories by using a layered neural network to conserve associative strength (Kehoe, 1988). The top portion of Figure 5 shows such a network. In this network, initial CR ac- quisition relies on a sequence of two associative links. During initial CS-US pairings, a stimulus-specific link between the CS and an intermediate "hidden" unit (X) develops first. When that link becomes strong enough, a link between the $\mathrm{X}$ unit and a second associative unit $(\mathrm{Y})$ is then developed. CRs begin to appear once the CS-X and the $\mathrm{X}-\mathrm{Y}$ connections both become strong enough that the $\mathrm{CS}$ activates $\mathrm{X}$ and then $\mathrm{X}$ activates $\mathrm{Y}$. The output of the $\mathrm{Y}$ unit feeds into motor units that drive the CR. At the beginning of extinction, both the $\mathrm{CS}-\mathrm{X}$ and the $\mathrm{X}-\mathrm{Y}$ connections would weaken. As the CS-X connection becomes too weak to activate the $\mathrm{X}$ unit, the $\mathrm{X}-\mathrm{Y}$ connection would be protected from further extinction. Consequently, a large portion of the $\mathrm{X}-\mathrm{Y}$ connection would be conserved. In reacquisition training, the CR would reappear quickly when the $\mathrm{CS}-\mathrm{X}$ connection becomes strong enough to activate $\mathrm{X}$ and, hence, to activate the largely intact $\mathrm{X}-\mathrm{Y}$ connection.

In summary, unlearning mechanisms, combined with mechanisms for conserving associative strength, can explain between-session recovery and rapid reacquisition. The lower portion of Figure 5, for example, shows a neural network that combines the multiple parallel associative connections postulated by stimulus sampling theory and the serial connections postulated in a layered network model. This particular combined model, unfortunately, still has the limitations of stimulus-sampling theory. However, the failings of stimulus-sampling theory do not doom unlearning theories in general or layered networks in particular. As will be discussed in the concluding section of this article, stimulus-sampling theory can be removed from this network, and a form of nonassociative loss can be added to provide a more satisfactory account of the withinsession declines and between-session increases seen in the present experiments.

\section{New-Learning Theories}

New-learning theories are a large, disparate class, but as their name implies, they all contend that new associations are formed when the US is altered. Historically, newlearning theories stem from Pavlov's (1927) proposition that the absence of the US in extinction leads to the development of inhibition. Inhibition, in turn, suppresses expression of the CR, while leaving the underlying excitatory association intact. Pavlov's conception of inhibition included both a labile nonassociative form (pp. 60-61) and a more permanent associative type (pp. 68-87). Later, Hull (1943, pp. 284, 300) made a similar distinction between a transient nonassociative form, which he called reactive inhibition $\left(\mathrm{I}_{\mathrm{R}}\right)$, and a more permanent associative form $\left({ }_{S} I_{R}\right)$. The accumulation of $I_{R}$ within a session and its dissipation between sessions was responsible for spontaneous recovery, whereas the acquisition of ${ }_{S} I_{R}$ was responsible for the eventual elimination of responding across extinction sessions.

Recent excitation-inhibition theories have largely jettisoned nonassociative inhibition and have focused on the 
associative form of inhibition as the source of CR extinction (Bouton, 1993; Falls, 1998; Klopf, 1988; Konorski, 1948, pp. 138-149; Pearce \& Hall, 1980; Wagner \& Brandon, 1989). ${ }^{1}$ In place of nonassociative inhibition, these theories have used a variety of ancillary assumptions to explain spontaneous recovery. For example, Konorski (1948, p. 84) postulated that, early in extinction, associative inhibition is weak and subject to regression over time, in comparison with the established excitatory connection. With continued extinction, however, the inhibitory connection becomes more firmly fixed and no longer subject to regression. In contrast, Bouton has contended that associative inhibition acquired during extinction is especially sensitive to contextual control. Hence, spontaneous recovery arises from time-related regression in context from the end of each extinction session back to the context prevailing during acquisition sessions.

Excitation-inhibition theories might seem to have little to say about reductions in US intensity. As usually depicted, there is a qualitative distinction between the absence of the US and the presence of the US. The absence of the US engages the inhibitory process, whereas a detectable US engages the excitatory process. However, excitation-inhibition models can be related to associative interference theories (Bouton, 1991; Konorski, 1967; Robbins, 1990; Spear, 1971). These theories assume that acquisition training and CS-alone extinction establish competing associations for reinforcement and nonreinforcement. For example, Konorski (1967) substituted excitatory associations between the CS and a no-US center for inhibitory connections in his earlier theory (Robbins, 1990). By the same token, USs of different intensity could acquire distinctive associations with a CS. Hence, in Stage 2 of the present experiments, the expression of an association based on a strong US would suffer similar interference whether the new association was based on a weak US or the complete absence of the US.

Although new-learning theories can explain the effects of US reduction on some aspects of spontaneous recovery, they run afoul of the same difficulties as stimulussampling theory-namely, explaining the within-session declines and between-session increases that appeared before US reduction and their persistence following US reduction. During initial acquisition, which has only a single US intensity, there would be no opportunity for a competing association to form. Associative interference theories suggest that, following US reduction, responding should eventually stabilize at a new asymptote as the new association gains strength and prevails over the old association.

New-learning theories also face difficulties in explaining rapid reacquisition. This problem is most obvious in connection with Hull's (1943) theory. He assumed that both excitatory and inhibitory associations were irreversible. Once the two associations were maximized, reacquisition would be impossible. The same problem would seem to be true for associative interference theories. Allowing for the reversal of new associations - for example, the extinction of inhibition-would convert new-learning theories into a hybrid with unlearning theories.

Some instances of reacquisition can be explained without relaxing the assumptions of new-learning theories by postulating (1) enhancement of the original excitatory association (Rescorla, 2001), or (2) unmasking of the original excitatory association by changes in context between extinction and reacquisition (Bouton, 1993). Although both these approaches preserve unlearning theory, they are not entirely satisfactory as explanations of rapid reacquisition. In the first case, the hypothesis that additional excitation is acquired would expect acquisition to proceed at the same rate as the original association. Certainly, additional mechanisms would be needed to accelerate the additional acquisition and yield rapid reacquisition.

In the case of contextual control hypotheses, rapid reacquisition can be explained when there is a pronounced change in context between extinction and reacquisition. Such a change would prevent retrieval of the association formed during extinction and, hence, would allow expression of the original excitatory association. This explanation, however, becomes tenuous when the global contexts for acquisition, extinction, and reacquisition are very similar. For example, Napier et al. (1992) conducted extinction of the NM response by increasing the CS-US interval from $250 \mathrm{msec}$ to $30 \mathrm{sec}$. Thus, they only changed the CS-US temporal relationship, while maintaining the same number and pattern of CS and US presentations. Subsequently, when the CS-US interval was returned to $250 \mathrm{msec}$, rapid reacquisition occurred and, in fact, was just as fast as reacquisition after CS-alone extinction.

A contextual control account for Napier et al. (1992) can be defended if the US forms part of the local context for the CS on a trial-by-trial basis, rather than contributing to the global context of an entire training session. As evidence that the US contributes to the local context, it has been shown that the US can act as a conditional cue (Barnet, Grahame, \& Miller, 1993; Schachtman \& Reilly, 1987). These localist approaches to contextual control, however, are more than a supplement to new-learning theories. Local context hypotheses share most of their features with an older theoretical tradition-namely, generalization decrement theories, which will be described and evaluated next.

\section{Generalization Decrement Theories}

Generalization decrement theories assume that extinction occurs because there is a progressive dissimilarity between the context of acquisition and extinction that prevents the CS from retrieving its excitatory association (Capaldi, 1967, 1994; Nevin, McLean, \& Grace, 2001; Ricker \& Bouton, 1996; Robbins, 1990). Most notably, Capaldi's (1994) sequential memory theory contends that the activation of associations is controlled not only by the immediate CS, but also by the episodic memory of cues arising from previous events in training sessions, especially the presence or absence of the US on previous trials. 
Hence, CRs disappear during CS-alone sessions because memories of no-US replace the memories of the US that prevailed during CS-US acquisition training. Betweensession increases occur because events distinctive to the start of training sessions-for example, handling of the animal - tend to restore the local context to one that is similar to acquisition training. Across repeated extinction sessions, the memories of the US even at the beginning of the session would be replaced, and the original excitatory association would no longer be retrieved. Thus, the CR would disappear altogether. Finally, a generalization decrement theory would explain rapid reacquisition as a reinstatement of the context for initial acquisition training caused by the reintroduction of the original US.

In its basic form, a generalization decrement hypothesis assumes that extinction and spontaneous recovery are pure performance effects that reflect variations in the success of retrieval, in which there is neither unlearning nor new learning. A generalization decrement hypothesis can explain the persistence of within-session declines and between-session increases that are seen after US intensity has been reduced. Specifically, the episodic memory of previous USs includes their intensity (Capaldi, 1994). Hence, when the US intensity paired with the CS is changed, there would be a generalization decrement in the retrieval of the excitatory association, depending on the dissimilarity between the new US intensity and the original US intensity. As with CS-alone extinction, the long distinctive gap between sessions would restore the context to that of initial acquisition training with the more intense US. Depending on the similarity between the memories of the stronger and of the weaker USs, the pattern of withinsession declines and between-session recovery could persist far longer than in CS-alone extinction. However, like stimulus-sampling and associative interference accounts of spontaneous recovery, a generalization decrement hypothesis would still expect responding to stabilize eventually as the memories of the new US intensity finally replace the memories of the original US at the start of the session.

Like the other theories, a generalization decrement hypothesis cannot explain the within-session declines and between-session increases that appeared when US intensity was unchanged, either in initial training for some groups or throughout training for others, in Experiments 1, 2, and 3. In Experiment 4, the US intensity alternated, but not in a way that would produce generalization decrements. Specifically, the randomization of trials during Stage 1 for Group 4-2 meant that both the 2-mA US and the 4-mA US equally predicted the pairing of the CS with the 4-mA US. Similarly, in Group 2-2 during both Stage 1 and Stage 2, both USs equally predicted the pairing of the $\mathrm{CS}$ with the 2-mA US. Hence, there was no change in the context within sessions that would reduce the ability of the CS to retrieve its associative strength.

Apart from these limitations, generalization decrement theories have been widely tested and have received considerable support, particularly in instrumental reward procedures (Capaldi 1994). Sadly, these theories may not be applicable to the rabbit NM response system. Rabbit NM conditioning has, to date, failed to show two key outcomes that would be expected if the episodic memories of previous trials provide cues on subsequent trials. First, it has not proved easy to use the US as a conditionalcue. Specifically, the rabbit NM preparation does not readily show single-alternation learning. In a single-alternation schedule, reinforced CS-US trials (R) are strictly alternated with nonreinforced $\mathrm{CS}$-alone trials $(\mathrm{N})$. This arrangement can be viewed as a feature negative discrimination, in which the US acts as the conditional cue for the CS-alone trial. The rabbit NM preparation has shown singlealternation learning only under highly restricted conditions-namely, when the RN interval was $10 \mathrm{sec}$ and the NR interval was $60 \mathrm{sec}$ (Hoehler \& Leonard, 1973). Other combinations, including equal RN and NR intervals of various lengths, have failed to produce single-alternation behavior in the NM response (Hoehler \& Leonard, 1973; Hoehler \& Thompson, 1979). Second, presentations of the US alone have consistently failed to reinstate an extinguished CR, even in a transient fashion (Napier et al., 1992; Weidemann \& Kehoe, 2001).

With respect to other preparations, the rabbit NM response may seem peculiar in its insensitivity to US-related contextual cues. This lack of sensitivity, however, is not a universal feature of conditioning in the rabbit.The acquisition of the rabbit NM response is sensitive to both the global context of a training session (Hinson, 1982; Kim, 1986; Saladin \& Tait, 1986) and the local context from non-US sources (Macrae \& Kehoe, 1995; Rogers \& Steinmetz, 1998; Weidemann \& Kehoe, 1997).More specifically, the rabbit does show single alternation in hippocampal activity even when NM response does not (Hoehler $\&$ Thompson, 1979), and the rabbit shows overt singlealternation behavior during appetitive conditioning of its jaw movement (Poulos, Sheafor, \& Gormezano, 1974). Even if the NM response is unique in its insensitivity to US-related contextualcues, the extinction and reacquisition results for it indicate that, although US-related contextual cues may have a widespread influence in other response systems, they are not essential to extinction phenomena. In summary, mechanisms depending on US-related contextual cues may be sufficient, but not necessary, for extinction and reacquisition.

\section{Nonassociative Losses in Responding}

The present findings strongly suggest that a performance factor tended to diminish responding within each session even when US intensity was unchanged. More specifically, the present results help to illuminate distinctions among three sources of nonassociative loss, which have been identified by Robbins (1990): (1) a reduction in CS processing (Pavlov, 1927, p. 391), (2) a reduction in US processing (Rescorla \& Cunningham, 1978; Rescorla \& Heth, 1975), and (3) the cumulative impact of repeated CR performance (Hull, 1943).

CS processing: Attention and associability. In the case of CS processing, Pavlov (1927) imagined that CS- 
alone presentations engender inhibition in the CS center. If Pavlov's hypothesis is taken at face value, it seems unlikely that the losses that occurred during CS-US pairings would engage this form of inhibition. Going beyond Pavlov, however, reductions in CS processing need not be tied only to CS-alone exposure. Modern attentional theories (Pearce \& Hall, 1980) contend that, during CS-US pairings, there is a loss of associability as the CS becomes more strongly associated with the US. This loss of associability is assumed to hinder further acquisition, but a loss of attention to the CS could also reduce expression of existing associative strength and lead to declines in responding during CS-US pairings.

To explain spontaneous recovery in attentional terms, there would have to be an overnight recovery in associability. This might seem to be a patently post hoc postulate, but it does yield at least one other testable deduction: If there is an overnight recovery of associability, one would expect learning to be most rapid on the first CS-US pairing of each session, after which the trial-by-trial learning rate would decline as associability declines. In agreement with this deduction, acquisition of the $\mathrm{CR}$ in the rabbit NM preparation is most rapid on a trial-by-trial basis when there is only one pairing in each session and less rapid as the number of trials per session increases (e.g., Kehoe, Cool, \& Gormezano, 1991).

US processing and representation. With regard to US processing, the available hypotheses contend that, during initial acquisition training, the animal not only forms a CS-US association, but also forms a representation of the US and its properties. Changes in this representation outside CS-US pairings have been found to alter the ability of the CS to elicit the CR, as for example, when a food US has been paired with the induction of nausea (Holland \& Rescorla, 1975). This hypothesis could explain the withinsession declines that occurred when US intensity was reduced. However, changes in the US representation cannot explain the within-session declines that occurred before the US intensity was reduced. If anything, during CS-US pairings, US representation should become stronger. Furthermore, in Experiment 4, the representation of the US was presumably fixed by holding constant the total pattern of exposure to the US, and yet within-session declines appeared in CR likelihood. In summary, a loss of US processing would not appear to be a contributor to the present results.

CR-based mechanisms. A CR-based mechanism can readily explain the within-session declines that were obtained when the US was unchanged, as well as when it was reduced. According to Hull (1943), $\mathrm{I}_{\mathrm{R}}$ accrues on each occurrence of the CR. During CR acquisition, the negative influence of $I_{R}$ can be masked by the growth in associative strength during CS-US pairings. In the present results, within-session declines reliably appeared in groups trained with the 4-mA US as their responding reached its asymptote and, presumably, associative growth tapered off. In groups trained with the 2-mA US, within-session declines appeared before asymptotic responding, indicating that the masking effect of associative growth is less when US intensity is low. Finally, during CS-alone extinction, the within-session declines were pronounced when there was no countervailing effect of CS-US pairings.

Hull's $I_{R}$ construct might seem indistinguishable from general motor fatigue. At times, Hull seemed to imply that $\mathrm{I}_{R}$ was akin to muscular fatigue (Hull, 1943, p. 279). Nevertheless, $I_{R}$ was formally tied to the $C R$, and not to the UR (Hull, 1943, p. 290). When $I_{R}$ is seen as a central CRspecific factor, it then becomes more understandable why (1) URs rarely showed within-session declines and/or between-session increases and (2) reductions in the number of trials per session and increases in the ITI did not appear to alter within-session declines.

\section{A Hybrid Model}

The findings of the present experiments suggest that extinction entails at least two superimposed mechanisms. First, there is a mechanism that determines the overall asymptote of responding from one session to the next as a function of US intensity, including the zero value. The second mechanism is responsible for the pattern of withinsession declines and between-session increases in responding that can appear even when the US is unchanged. As may be readily apparent, no single theory provides a sufficient account. A hybrid of associative and nonassociative mechanisms would seem to be needed.

To explain the present results, some mechanisms can be discounted as major contributors, some are questionable as contributors, and some seem plausible. Figure 6 shows a neural network that illustrates one way that the latter two categories of mechanisms could be represented in a hybrid model. At its core is a layered network like the one described in connection with unlearning theories. As was discussed previously, the layered network provides a more plausible account for rapid reacquisition in the rabbit NM preparation than do the contextual-control mechanisms envisioned in new-learning theories and generalization decrement theories.

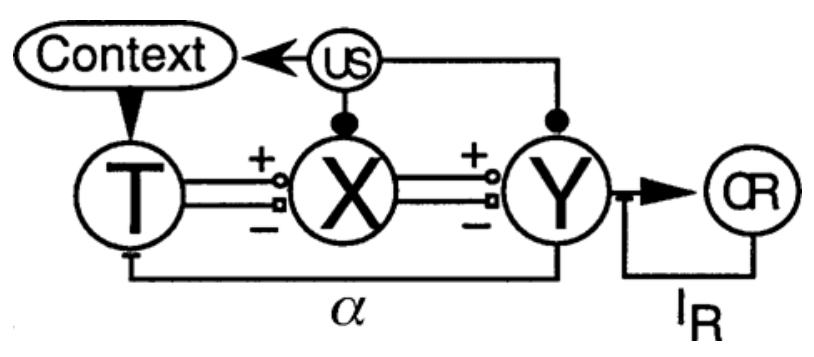

Figure 6. A layered network in which tone (T) has excitatory and inhibitory associative linkages with an intermediate unit $(X)$, which in turn has excitatory and inhibitory associative linkages with an output unit (Y).The unconditioned stimulus (US) sends inputs to the $X$ unit, $Y$ unit, and context inputs. There are inhibitory feedback loops (1) from the $Y$ output to the $T$ input unit and (2) from the motor units (CR) to the Y output. 
Figure 6 does include an inhibitory associative linkage in the CS-X and $\mathrm{X}-\mathrm{Y}$ layers. These linkages have been added to show that unlearning and new-learning mechanisms can operate in parallel to control the asymptotic level of responding. At least three alternative learning mechanisms could use parallel excitatory and inhibitory linkages. First, Klopf (1988) has contended that extinction and reacquisition of a CR entails concurrent changes in both types of linkage. Second, Rescorla (2001), who assumed nonreversible linkages, has argued that extinction entails the addition of inhibition and reacquisition entails the addition of excitation. Third, to account for increases in the speed of successive acquisitions and extinctions (Smith \& Gormezano, 1965), increases in the learning rates of either or both types of linkage may be implemented through ancillary mechanisms that are sensitive to frequent changes in the rate of reinforcement (Gallistel \& Gibbon, 2000; Gallistel, Mark, King, \& Latham, 2001).

The model includes the two most plausible nonassociative mechanisms for explaining the pattern of withinsession declines and between-session increases seen in the present experiments-namely, losses in CR generation and CS processing. The loss in CR generation is depicted as an inhibitory loop $\left(I_{R}\right)$ from the $C R$ unit to the output from the $\mathrm{Y}$ unit. Thus, as CRs are generated during a training session, further CRs would be inhibited. Similarly, the loss in CS processing is depicted as an inhibitory loop $(\alpha)$ from the output of the Y unit to the CS unit. In addition, the loss of CS processing could entail either an inhibitory loop from the CS unit back to itself or a change in the learning rate in the CS-X associative connections, as in Pearce and Hall's (1980) model. Irrespective of the precise details, losses in CR generation and CS processing would act in concert to dampen both the learning rate and the ability of the CS to elicit the CR as the total associative output from the system grows.

Finally, the network in Figure 6 acknowledges the potential role of local and global contexts, which have proved to be major contributors in the acquisition, extinction, and reacquisition of many response systems. As depicted in Figure 6, the exact role of context is deliberately left vague. It could act in compound with the CS as envisioned in generalization decrement theory, as a moderator for expressing inhibitory associations (Bouton \& Bolles, 1985; Bouton \& Nelson, 1998), or as a comparator in expressing a three-way set of excitatory associations among the context, CS, and US (e.g., Gunther, Denniston, \& Miller, 1998; Miller \& Matzel, 1989; Yin, Grahame, \& Miller, 1993).

In conclusion, the present empirical results and a consideration of the available theories reveal two key points about conditioning. First, removal of the US appears to be on a continuum with US intensity. That is to say, extinction can be viewed as a change in responding resulting from presentation of a very, very weak US, rather than being qualitatively different from response acquisition. Second, the learning apparatus contains multiple mechanisms for reg- ulating the expression of associative strength in overt CRs while, at the same time, conserving excitatory associations as they become established. From this perspective, extinction is an example of an extreme downward regulation of responding that can be relatively easily reversed.

\section{REFERENCES}

Aguado, L., de Brugada, I., Hall, G., \& Agate, L. (2001). Tests for inhibition after extinction of a conditioned stimulus in the flavour aversion procedure. Quarterly Journal of Experimental Psychology, 54B, 201-217.

Aoy ama, K., \& McSweeney, F. K. (2001). Habituation may contribute to within-session decreases in responding under high-rate schedules of reinforcement. Animal Learning \& Behavior, 29, 79-91.

Ayres, J. J. B., Moore, J. W., \& Vigorito, M. (1984). Hall and Pearce negative transfer: Assessments in conditioned suppression and nictitating membrane conditioning experiments. Animal Learning \& Behavior, 12, 428-438.

Barnet, R. C., Grahame, N. J., \& Miller, R. R. (1993). Local context and the comparator hypothesis. Animal Learning \& Behavior, 21, 1-13.

Booream, C. D., \& Flowers, J. V. (1974). Positive and negative contrast in successive nondifferential conditioning: A new approach to between-subjects methodology. Journal of General Psychology, 46, 63-68.

Bouton, M. E. (1991). Context and retrieval in extinction and in other examples of interference in simple associative learning. In L. Dachowski \& C. F. Flaherty (Eds.), Current topics in animal learning: Brain, emotion, and cognition (pp. 25-49). Hillsdale, NJ: Erlbaum. Bouton, M. E. (1993). Context, time, and memory retrieval in the interference paradigms of Pavlovian conditioning. Psychological Bulletin, 114, 80-99.

Bouton, M. E., \& Bolles, R. C. (1985). Contexts, event-memories and extinction. In P. D. Balsam \& A. Tomie (Eds.), Context and learning (pp. 133-166). Hillsdale, NJ: Lawrence Erlbaum.

Bouton, M. E., \& Nelson, J. B. (1998). The role of context in classical conditioning: Some implications for cognitive behavior therapy. In W. O'Donohue (Ed.), Learning and behavior therapy (pp. 59-84). Boston: Allyn \& Bacon.

Bouton, M. E., \& Swartzentruber, D. (1986). Analysis of the associative and occasion-setting properties of contexts participating in a Pavlovian discrimination. Journal of Experimental Psychology: Animal Behavior Processes, 12, 333-350.

Bouton, M. E., \& Swartzentruber,D. (1989). Slow reacquisition following extinction: Context, encoding, and retrieval mechanisms. Journal of Experimental Psychology: Animal Behavior Processes, 15, 4353.

Bush, R. R., \& Mosteller, F. A. (1951). A mathematical model for simple learning. Psychological Review, 58, 313-323.

CAPALDI, E. J. (1967). A sequential hypothesis of instrumental learning. In K. W. Spence \& J. T. Spence (Eds.), The psychology of learning and motivation (Vol. 1, pp. 67-91). New York: Academic Press.

CAPALDI, E. J. (1994). The sequential view: From rapidly fading stimulus traces to the organization of memory and the abstract concept of number. Psychonomic Bulletin \& Review, 1, 156-181.

CAPAldi, E. J., \& ZFF, D. R. (1969). Schedule of partial reward and the negative contrast effect. Journal of Comparative \& Physiological Psychology, 68, 593-596.

Carlton, J. L., Mitchell, K. G., \& Schachtman, T. R. (1996). Conditioned inhibition produced by extinction of a conditioned stimulus. Learning \& Motivation, 27, 335-361.

Collier, G., Knarr, F. A., \& Marx, M. H. (1961). Some relations between the intensive properties of the consumatory response and reinforcement. Journal of Experimental Psychology, 62, 484-495.

Cox, W. M. (1975). A review of recent incentive contrast studies involving discrete-trial procedures. Psychological Record, 25, 373-395.

Estes, W. K. (1955). Statistical theory of spontaneous recovery and regression. Psychological Review, 62, 145-154. 
FALls, W. A. (1998). Extinction: A review of theory and evidence suggesting that memories are not erased with nonreinforcement. In W. O. Donohue (Ed.), Learning and behavior therapy (pp. 205-229). Boston: Allyn \& Bacon.

FlaherTy, C. F. (1982). Incentive contrast: A review of behavioral changes following shifts in reward. Animal Learning \& Behavior, 10, 409-440.

Gallistel, C. R., \& GibBon, J. (2000). Time, rate, and conditioning. Psychological Review, 107, 289-344.

Gallistel, C. R., Mark, T. A. King, A. P., \& Latham, P. E. (2001). The rat approximates an ideal detector of changes in rates of reward: Implications for the law of effect. Journal of Experimental Psychology: Animal Behavior Processes, 27, 354-372.

Gibbs, C. M., Latham, S. B., \& Gormezano, I. (1978). Classical conditioning of the rabbit nictitating membrane response: Effects of reinforcement schedule on response maintenance and resistance to extinction. Animal Learning \& Behavior, 6, 209-215.

Gluck, M. A., \& Thompson, R. F. (1987). Modeling the neural substrates of associative learning and memory: A computational approach. Psychological Review, 94, 176-191.

Gormezano, I. (1966). Classical conditioning. In J. B. Sidowski (Ed.), Experimental methods and instrumentation in psychology (pp. 385420). New York: McGraw-Hill.

Gormezano, I., \& GibBs, C. M. (1988). Transduction of the rabbit's nictitating membrane response. Behavior Research Methods, Instruments, \& Computers, 20, 18-21.

Gunther, L. M., Denniston, J. C., \& Miller, R. R. (1998). Renewal of comparator stimuli. Learning \& Motivation, 29, 200-219.

Hart, J. A., Bourne, M. J., \& Schachtman, T. R. (1995). Slow reacquisition of a conditioned taste aversion. Animal Learning \& Behavior, 23, 297-303.

Hinson, R. E. (1982). Effects of UCS preexposure on excitatory and inhibitory rabbit eyelid conditioning: An associative effect of conditioned contextual stimuli. Journal of Experimental Psychology: Animal Behavior Processes, 8, 49-61.

Hoehler, F. K., \& LeONARD, D. W. (1973). Classical nictitating membrane conditioning in the rabbit (Oryctolagus cuniculus): Single alternation with differential intertrial intervals. Journal of Comparative \& Physiological Psychology, 85, 277-288.

Hoehler, F. K., \& Leonard, D. W. (1981). Motivationalvs. associative role of the US in classical conditioning of the rabbit's nictitating membrane response. Animal Learning \& Behavior, 9, 239-244.

Hoehler, F. K., \& Thompson, R. F. (1979). The effect of temporal single alternation on learned increase in hippocampal unit activity in classical conditioning of the rabbit nictitating membrane response. Physiological Psychology, 7, 345-351.

Holland, P. C., \& Rescorla, R. A. (1975). The effect of two ways of devaluing the unconditioned stimulus after first- and second-order appetitive conditioning. Journal of Experimental Psychology: Animal Behavior Processes, 1, 355-363.

Hull, C. L. (1943). Principles of behavior. New York: Appleton-CenturyCrofts.

KeHOE, E. J. (1988). A layered network model of associative learning: Learning-to-learn and configuration. Psychological Review, 95, 411433.

Kehoe, E. J., Cool, V., \& Gormezano, I. (1991). Trace conditioning of the rabbit's nictitating membrane response as a function of CS-US interstimulus interval and trials per session. Learning \& Motivation, 22, 269-290.

Kehoe, E. J., \& Weidemann, G. (2001, July). Reduction but not elimination of savings after extinction in classical conditioning of the rabbit. Paper presented at the 2nd Australian Learning Group Conference, Magnetic Island, Queensland.

KIM, K. S. (1986). Effects of context manipulation on latent inhibition: A study on the nature of context in classical conditioning. Korean Journal of Psychology, 5, 75-86.

KLOPF, A. H. (1988). A neuronal model of classical conditioning. Psychobiology, 16, 85-125.

KonORSKI, J. (1948). Conditioned reflexes and neuron organization. Cambridge: Cambridge University Press.
KONORSKI, J. (1967). Integrative activity of the brain: An interdisciplinary approach. Chicago: University of Chicago Press.

MACKINTOSH, N. J. (1975). A theory of attention: Variation in the associability of stimuli with reinforcement. Psychological Review, 82, 276-298.

Macrae, M., \& Kehoe, E. J. (1995). Transfer between conditional and discrete discriminations in conditioning of the rabbit nictitating membrane response. Learning \& Motivation, 26, 380-402.

Macrae, M., \& Kehoe, E. J. (1999). Savings after extinction in conditioning of the rabbit's nictitating membrane response. Psychobiology, 27, 85-94.

Mazur, J. E. (1996). Past experience, recency, and spontaneous recovery in choice behavior. Animal Learning \& Behavior, 24, 1-10.

McSweeney, F. K., \& Roll, J. M. (1993). Responding changes systematically within sessions during conditioning procedures. Journal of the Experimental Analysis of Behavior, 60, 621-640.

Medina, J. F., Garcia, K. S., \& Mauk, M. D. (2001). A mechanism for savings in the cerebellum. Journal of Neuroscience, 21, 4081-4089.

Miller, R. R., \& Matzel, L. D. (1989). Contingency and relative associative strength. In S. B. Klein \& R. R. Mowrer (Eds.), Contemporary learning theories: Pavlovian conditioning and the status of traditional learning theory (pp. 61-84). Hillsdale, NJ: Erlbaum.

Napier, R. M., Macrae, M., \& Kehoe, E. J. (1992). Rapid reacquisition in conditioning of the rabbit's nictitating membrane response. Journal of Experimental Psychology: Animal Behavior Processes, 18, 182-192.

Nevin, J. A., McLean, A. P., \& Grace, R. C. (2001). Resistance to extinction: Contingency termination and generalization decrement. Animal Learning \& Behavior, 29, 176-191.

PAVlov, I. P. (1927). Conditioned reflexes: An investigation of the physiological activity of the cerebral cortex (G. V. Anrep, Trans.). London: Oxford University Press.

Pearce, J. M., \& Hall, G. (1980). A model for Pavlovian learning: Variations in the effectiveness of conditioned but not of unconditioned stimuli. Psychological Review, 87, 532-552.

Poulos, C. X., Sheafor, P. J., \& Gormezano, I. (1974). Classical appetitive conditioning of the rabbit's (Oryctolagus cuniculus) jawmovement response with a single-alternation schedule. Journal of Comparative \& Physiological Psychology, 75, 231-238.

Rescorla, R. A. (2001). Retraining of extinguished Pavlovian stimuli. Journal of Experimental Psychology: Animal Behavior Processes, 27, 115-124.

Rescorla, R. A., \& Cunningham, C. L. (1978). Recovery of the US representation over time during extinction. Learning \& Motivation, $\mathbf{9}$, 373-391.

Rescorla, R. A., \& Heth, C. D. (1975). Reinstatement of fear to an extinguished conditioned stimulus. Journal of Experimental Psychology: Animal Behavior Processes, 1, 88-96.

Rescorla, R. A., \& Wagner, A. R. (1972). A theory of Pavlovian conditioning: Variations in the effectiveness of reinforcement and nonreinforcement. In A. H. Black \& W. F. Prokasy (Eds.), Classical conditioning II (pp. 64-99). New York: Appleton-Century-Crofts.

Ricker, S. T., \& Bouton, M. E. (1996). Reacquisition following extinction in appetitive conditioning. Animal Learning \& Behavior, 24, 423-436.

RobBins, S. J. (1990). Mechanisms underlying spontaneous recovery in autoshaping. Journal of Experimental Psychology: Animal Behavior Processes, 16, 235-249.

Rogers, R. F., \& Steinmetz, J. E. (1998). Contextually based conditional discrimination of the rabbit eyeblink response. Neurobiologyof Learning \& Memory, 69, 307-319.

SAladin, M. E., \& TAIT, R. W. (1986). US preexposures retard excitatory and facilitate inhibitory conditioning of the rabbit's nictitating membrane response. Animal Learning \& Behavior, 14, 121-132.

SCANDRETt, J., \& Gormezano, I. (1980). Microprocessor control and A/D data acquisition in classical conditioning. Behavior Research Methods \& Instrumentation, 12, 120-125.

Schachtman, T. R., \& Reilly, S. (1987). The role of local context in autoshaping. Learning \& Motivation, 18, 343-355.

Schreurs, B. G., OH, M. M., Hirashima, C., \& Alkon, D. L. (1995). Conditioning-specific modification of the rabbit's unconditioned nictitating membrane response. Behavioral Neuroscience, 1, 24-33. 
Schreurs, B. G., Shi, T., Pineda, S., III, \& Buck, D. L. (2000). Conditioning the unconditioned response: Modification of the rabbit's (Oryctolagus cuniculus) unconditioned nictitating membrane response. Journal of Experimental Psychology: Animal Behavior Processes, 26, 144-156.

SMith, M. C. (1968). CS-US interval and US intensity in classical conditioning of the rabbit's nictitating membrane response. Journal of Comparative \& Physiological Psychology, 66, 679-687.

Sмiтh, M. [C.], \& Gormezano, I. (1965). Effects of alternating classical conditioning and extinction sessions on the conditioned nictitating membrane response of the rabbit. Psychonomic Science, 3, 91-92.

SPEAR, N. E. (1971). Forgetting as retrieval failure. In W. K. Honig \& P. H. R. James (Eds.), Animal memory (pp. 45-109). New York: Academic Press.

SPENCE, K. W. (1958). An emotionally based theory of drive (D) and its relation to performance in simple learning situations. American Psychologist, 13, 131-141.

Spence, K. W., Haggard, D. F., \& Ross, L. E. (1958). UCS intensity and the associative (habit) strength of the eyelid CR. Journal of Experimental Psychology, 55, 404-411.

Sutton, R. S., \& Barto, A. G. (1981). Toward a modern theory of adaptive networks: Expectation and prediction. Psychological Review, 88, 135-171.

Sutton, R. S., \& Barto, A. G. (1990). Time-derivative models of Pavlovian reinforcement. In M. Gabriel \& J. W. Moore (Eds.), Learning and computationalneuroscience (pp. 497-537). Cambridge, MA: MIT Press.

Tait, R. W., Kehoe, E. J., \& Gormezano, I. (1983). Effects of US duration on classical conditioning of the rabbit's nictitating membrane response. Journal of Experimental Psychology: Animal Behavior Processes, 9, 91-101.
Wagner, A. R., \& Brandon, S. E. (1989). Evolution of a structured connectionist model of Pavlovian conditioning(AESOP). In S. B. Klein \& R. R. Mowrer (Eds.), Contemporary learning theories: Pavlovian conditioning and the status of traditional learning theory (pp. 149190). Hillsdale, NJ: Erlbaum.

Weidemann, G., \& Kehoe, E. J. (1997). Transfer and counterconditioning of conditional control in the rabbit nictitating membrane response. Quarterly Journal of Experimental Psychology, 50B, 295316.

Weidemann, G., \& Kehoe, E. J. (2001, July). Concurrent recovery of an extinguished conditioned response in the rabbit. Paper presented at the 2nd Australian Learning Group Conference, Magnetic Island, Queensland.

Yin, H., Grahame, N. J., \& Miller, R. R. (1993). Extinction of comparator stimuli during and after acquisition: Differential facilitative effects on Pavlovian responding. Learning \& Motivation, 24, 219-241.

ZEAMAN, D. (1949). Response latency as a function of the amount of reinforcement. Journal of Experimental Psychology, 39, 466-483.

\section{NOTE}

1. Pearce and Hall (1980) have proposed a two-stage attentional model that allows changes in CS processing as well as inhibitory learning to contribute to extinction phenomena. The role of CS processing is described later in this discussion under the heading of nonassociative losses in responding.

(Manuscript received September 19, 2001; revision accepted for publication February 27, 2002.) 